\title{
Configuración semiótica del cuerpo terrorífico en el cine de horror.
}

\section{A semiotic configuration of the terrifying body in horror cinema.}

\author{
Esta obra está bajo una Licencia Creative Commons Atribución 4.0 Internacional.
} DOI: $10.32870 /$ sincronia.axxii.n74.25b18

\author{
José Reyes González Flores \\ Departamento de Letras / Universidad de Guadalajara \\ josereyesgonzalez@hotmail.com \\ (MÉXICO)
}

Recibido: $31 / 03 / 2018$

Revisado: $22 / 04 / 2018$

Aprobado: $15 / 06 / 2018$

\section{RESUMEN}

El horror, la angustia, el miedo y la exaltación son reacciones que los seres humanos manifiestan cuando se sienten amenazados por aquellos seres que han traspasado los límites naturales o sociales. Un cuerpo mutilado, un cuerpo supurante, un cuerpo deforme, una trasformación corporal extrema induce al horror. Además, los lugares apartados y en penumbras provocan la sensación de guardar secretos y, esos misterios provocan los imaginarios más aberrantes, macabros y espeluznantes. No se trata tan solo de un juego de adjetivos, porque presentir a alguien detrás de uno provoca miedo. El horror, por tanto, es esa sensación percibida y sentida por los seres humanos, en cambio el terror es la realización de ese horror, ya no es la presencia que brota de la oscuridad o la encarnación de un cuerpo mutilado y amorfo, sino la realización del horror. El horror se siente en la piel, se presiente, pero cuando se manifiesta y entra en contacto con las personas, entonces el terror se magnifica. El cine de horror ha traído del imaginario monstruos, posesos, personajes que se alimentan de sangre y carne humana, por eso este trabajo abre una línea de investigación Semiótica con la cual, a partir de la configuración, permite construir inventarios de las figuras discursivas del cuerpo horrífico. De tal manera, la Semiótica de cuarta generación -Semiótica 4 [s4]- aporta los referentes teóricos y metodológicos para explicar las figuras de los cuerpos terroríficos en el cine de horror. El corpus en estudio es un breve compendio de textos cinematográficos ya clásicos en el cine de horror.

Palabras clave: Semiótica. Cuerpo terrorífico. Figura. Sintaxis discursiva figurativa.

\section{ABSTRACT}


The horror, the angst, the fear and the exaltation are all reactions that human beings manifest when they feel threatened for those beings that have overstepped the natural and social limits. A mutilated body, a festered body, a deformed body, an extreme corporal transformation induces horror. In addition, the isolated and dreary places cause the feeling of secrets being hidden and those mysteries cause the most abnormal, macabre and horrifying imaginaries. It's not only about a game of adjectives, because to sense a feeling of having someone behind one's self, causes fear. The horror, therefore, it's that sensation perceived and felt by human beings, whereas terror is the realization of that horror, it's not the presence that arises from the darkness or the incarnation of a mutilated and amorphous body anymore, but the realization of the horror. The horror can be felt in the skin, you can sense it, but when it manifests and gets in contact with people, then the horror magnifies. The horror cinema has brought from the imaginary all kinds of monsters, possessions, characters that feed on human flesh and blood, that's why this work opens a line of investigation in Semiotics with which, based on the configuration, allows building discursive figures of the horrific body inventories. In such way, fourth generation semiotics - Semiotics 4 [s4] - contributes with its theoretical and methodological guides to explain the terrifying bodies' figures in horror cinema. The corpus under study is a brief summary of cinematographic texts that are already a classic in the horror cinema.

Keywords: Semiotics. Terrifying body. Figure. Figurative discursive syntax.

\section{Entre el horror y el terror: una guía reflexiva}

Imaginemos el encuentro con un ser horrendo. Imaginemos la huida masiva, los gritos, las personas que escapan, que caen. Percibamos, y por qué no, sintamos la desesperación, el sobresalto, la inquietud y el temor que deja en pasmo a nuestro cuerpo. Acéptese todo esto porque los cuerpos terroríficos siempre han provocado morbo. El cuerpo terrífico, en la actualidad, aparece como una simple descripción adjetival, ya que se queda en el vacío de lo real, no obstante, lo monstruoso ha dejado huella en los imaginarios. Si el terror ha modificado su semántica, ¿por qué las personas buscan los textos de horror? ¿Qué interés, ante la costumbre de los cuerpos horríficos, tiene el lector por las películas de "miedo"? ¿Qué motiva al espectador para ir al encuentro del horror si el mundo del siglo XXI ofrece razones para no morir horrorizado? Así que estas indagaciones toman como objeto de estudio al cuerpo hórrido en el llamado cine terror. El cine de horror es un objeto estético gratificante que pone al lector ante la ansiedad, el masoquismo y los cuerpos supurantes. Incluso, lleva al espectador por los caminos más oscuros, de ahí que el cine sea un reto a la identidad del ser humano. De tal manera, el lector cinematográfico es colocado entre las fronteras 
de lo normal y lo anormal; entre lo social y lo salvaje, pues estos son elementos detonadores del placer por el texto.

El cuerpo terrorífico resulta de un ejercicio imaginativo-figurativo, ya sea por las excreciones corporales, los defectos físicos, las deformidades de los rostros o la psiquis moralmente contraria a las normas social. Sin lugar a dudas, el cuerpo horrísono incide en las isotopías semióticas de lo asocial, pues lo detestable y lo indeseable hacen del cuerpo, en el cine de horror, un cuerpo amorfo. Resulta así un objeto-cuerpo axiologizado como malvado y terrible, por lo cual, lo horrendo implica una disolución de lo socialmente aceptado. Por simplicidad, se expone, a usted lector, la siguiente hipótesis: Describir las figuras discursivas del cuerpo terrorífico en el cine de horror. De ahí que será conveniente establecer los límites entre el horror y el terror. El primero alude a lo monstruoso, a lo atroz y a lo intangible, de tal forma que provoca miedo, inquietud y sobresalto como lo hace, por ejemplo, lo demoniaco en las posesiones corporales. El segundo, -el terror- involucra a la afectividad sobrecogedora del miedo, por ello, toma al cuerpo como referencia, ya que impide al pensamiento racional actuar como tal. Es decir, el horror es aprensivo cuando se siente el temor por los lugares lúgubres o por la oscuridad, de ambos escenarios se presiente el mal. El horror presentifica al asesino, en cambio, el terror aparece cuando ese asesino inicia la persecución, de tal manera que invade el espacio social y corporal de quien ha percibido esa presencia. En últimas, se puede afirmar que el terror es la realización del horror.

El horror es sensorial, se percibe, algo está ahí; por otra parte, el terror se manifiesta en la corporalidad, si es la propia, con el pasmo o con la huida; si es en el cuerpo-otro, el cuerpo será terrorífico. Es por eso que el horror funda recorridos semánticos discursivos como el miedo, la angustia, el asombro o el suspenso. Un cuerpo monstruoso o un cuerpo hipertrofiado rompen la lógica del orden social, por tanto, causan inquietud -horror-. Para explicar la construcción de las figuraciones y la significación discursiva del cuerpo horroroso se partirá de los preceptos iniciados por la Escuela de París, los cuales fueron dados a conocer en Modes du sensible et formes sémiotiques y en Modes du sensible, formes sémiotiques: la sémiotiques du corps, en particular, las 
exposiciones realizadas por Jacques Fontanille en Soma y soma. Figuras semióticas del cuerpo (2008), sin dejar de lado los aportes de otras disciplinas que se han ocupado del cuerpo como procesos culturales de la significación. Dicho esto, la Semiótica de cuarta generación -Semiótica 4 [s4]- será el camino para describir la configuración del cuerpo terrorífico en un corpus reducido de películas del cine de horror (Nosferatu, el vampiro, 1922; El exorcista, 1975; Vinieron de dentro..., 1975; Allien, el octavo pasajero, 1979; y Drácula, 1992). La Semiótica 4 [s4] permitirá trazar las proyecciones del horror, pues lo primero que se produce es un efecto de sentido en lo sentido [efecto patémico]. Incluso, la afectividad es causante del horror más intenso, cuya primera reacción corporal es huir de todo aquello considerado amenazante. Lo mismo ocurre con lo siniestro, con la muerte y con lo morboso, ya que causan miedo.

El estudio del cuerpo como objeto semiótico es reciente; las teorías y las metodologías hacen presencia hacia fines de siglo XX. El resultado es la puesta en escena de una Semiótica somática donde el objeto semiótico instaurado permite las relaciones entre soma y sema -cuerpo y significación-. La sola presencia del cuerpo en los estudios de la significación pone en funcionamiento las figuras semióticas de la corporeidad; estas están delimitadas por las figuras del discurso, las figuras de la sustancia de la expresión y por las figuras de la sustancia del contenido. La figura refiere a un no-signo, es decir, a un núcleo semántico estable, pues este expone una relación semántico-pragmática entre el signo -no necesariamente lingüístico- y la realidad. No obstante, la figura tiende a estabilizar el significante, cuyo resultado no es más que la represenciación de lo real, es decir, se trata de una representación de las presencias cuyos dispositivos semióticos permiten describir la significación. Sin embargo, para hacer presentes las figuras del mundo se hace necesario que la figura -núcleo semántico estable- se humanice. En consecuencia, los valores culturales, sociales e históricos ofrecen lo figural como unidad semiótica, en otras palabras, la figura humanizada. Lo humano presente en la nueva figura -lo figural- permite esbozar el conjunto de valores que dan sentido a la configuración de las presencias del mundo como un todo significante. 
El objeto semiótico refiere a todo fenómeno social de la significación, de tal manera que el cuerpo, como objeto-significación, deviene en sustancia semiótica capaz de poner en funcionamiento la semiosis. Además, el cuerpo, como práctica significante, es la experiencia sensible que se pone en contacto con el mundo, ya sea para ir hacia él o para que el mundo se desplace hacia el cuerpo. De tal forma que se instaura una tensión entre el cuerpo y el mundo o entre el mundo y el cuerpo, lo cual permite la construcción de lo figural para asentir a la explicación las figuras discursivas. Si existe un cuerpo, existe afectividad. Si hay un cuerpo, entonces hay un sujeto que percibe y siente el mundo. De tal manera que la antigua tesis de Descartes de "Lo que es pasión con respecto de un sujeto es siempre acción respecto de otro" (1994, p. 83). Sin embargo, se puede ir más allá; si toda acción produce un efecto de sentido en lo sentido, esa afectividad se manifiesta en el cuerpo. En otras palabras, la acción-pasión provoca tensiones que dejan su impronta en el cuerpo del sujeto que percibe y que siente. En el mundo posible cinematográfico, en particular, en el cine de horror, existe un cuerpo que siente y percibe el miedo, se trata de una persona horrorizada. Por otro lado, existe «alguien» que es la fuente de ese horror, es decir, un cuerpo horrífico. Así pues, la acción de un cuerpo horrendo es la causante de la afectividad -miedo, angustia, et sequens- en el otro cuerpo, el cual reacciona a ese sentimiento de horror.

El terror surge cuando la confrontación del bien y el mal encuentran realización en lo corporal, de ahí que el monstruo es terrorífico, por antinomia personifica lo maligno. La monstruosidad solo es pertinente si se opone a lo que socialmente se considera normal, cotidiano y estable. En cambio, cuando lo normal y lo natural muestran alguna modificación, entonces rompen la estabilidad del mundo, con lo que las proyecciones de la anormalidad llegan al sujeto percibiente para acentuar el valor dramático de lo in-forme. Por ejemplo, las posesiones de un "cuerpo" por un "ente" maligno ponen al descubierto el terror, es ahí donde brotan las ansiedades, es decir, el "horror". Pero, ¿cuándo un cuerpo resulta horrendo? La solución más sencilla abre, por lo menos, dos sentidos. En primer lugar, la construcción de lo feo y lo grotesco del cuerpo físico. En segundo término, la caracterización de lo feo y lo grotesco en el cuerpo moral. La fealdad física como las 
deformaciones y la asimetría corporal activan el horror. Por otra parte, las excreciones, ya sea el babeo, la secreción purulenta o el vómito remiten a lo grotesco. Sin lugar a dudas, el cuerpo horrendo va de la fealdad a lo grotesco, por tanto, se opone a lo que la sociedad considera belleza. En cuanto a lo moral, es posible que el cuerpo sea bello, pero su moral se encuentra en los terrenos de la fealdad o de lo grotesco, como lo muestran los asesinos seriales o aquellas acciones que atentan contra lo socialmente establecido.

A la ecuación acción-pasión cabe agregarle un elemento más: acción-pasión-cuerpo. Lo cual implica que el cuerpo se transforma en una instancia de enunciación, ya sea el cuerpo de la acción o el cuerpo afectado. No es una casualidad el hecho de que el cuerpo, en la Semiótica 4 [s4], sea el centro de la referencia discursiva, el centro de donde emerge la significación o el centro de los movimientos corporales significantes. La instancia enunciante es más que un sujeto lingüístico, es un cuerpo vivo que traza el sentido, el cual no es direccional sino dinámico. Si se piensa en los aspectos elementales de la enunciación, desde las propuestas de Benveniste $(2004,2007)$, las de Greimas y Courtés (1982, 2004), las de Courtés (2007) hasta las de Fontanille (2001), se pudiese decir que la enunciación es un acto que pone en movimiento al lenguaje. En consecuencia, se distingue, por un lado, el acto de la enunciación, el cual hace que el discurso sea un objeto o hecho lingüístico, cuyos significados están dados de antemano. Pero se puede argüir que las instancias de la enunciación son más que personas lingüísticas. Por otro lado, cuando se accede a la enunciación en acto, se está ante la enunciación viviente, lo cual evidencia que la instancia del discurso es un sujeto que siente y que percibe, por tanto, tiene cuerpo y él pone en funcionamiento los procesos de significación.

La enunciación viviente no es un hecho, sino un proceso donde el cuerpo realiza una acción discursiva que afecta a otro-cuerpo. Las consecuencias son, por un lado, las pasiones y por otro, las manifestaciones somáticas que llevan la huella semiótica de esa afectividad. Entonces la ecuación acción-pasión-cuerpo entra en un proceso cursivo y decursivo: cuerpo-acción-pasión-cuerpo. Se puede decir que la enunciación instaura dos figuras, la primera es la del sujeto empírico, es decir, el 
cineasta; quien crea un enunciado -película-, para un lector. Tal conformación es un acto de la enunciación, pero, ¿qué existe dentro del Enunciado-película? Una enunciación en acto, es decir, aquellos dispositivos semióticos que posibilitan las significaciones del discurso en acto como procesos figurativos significantes, leamos la siguiente gráfica:

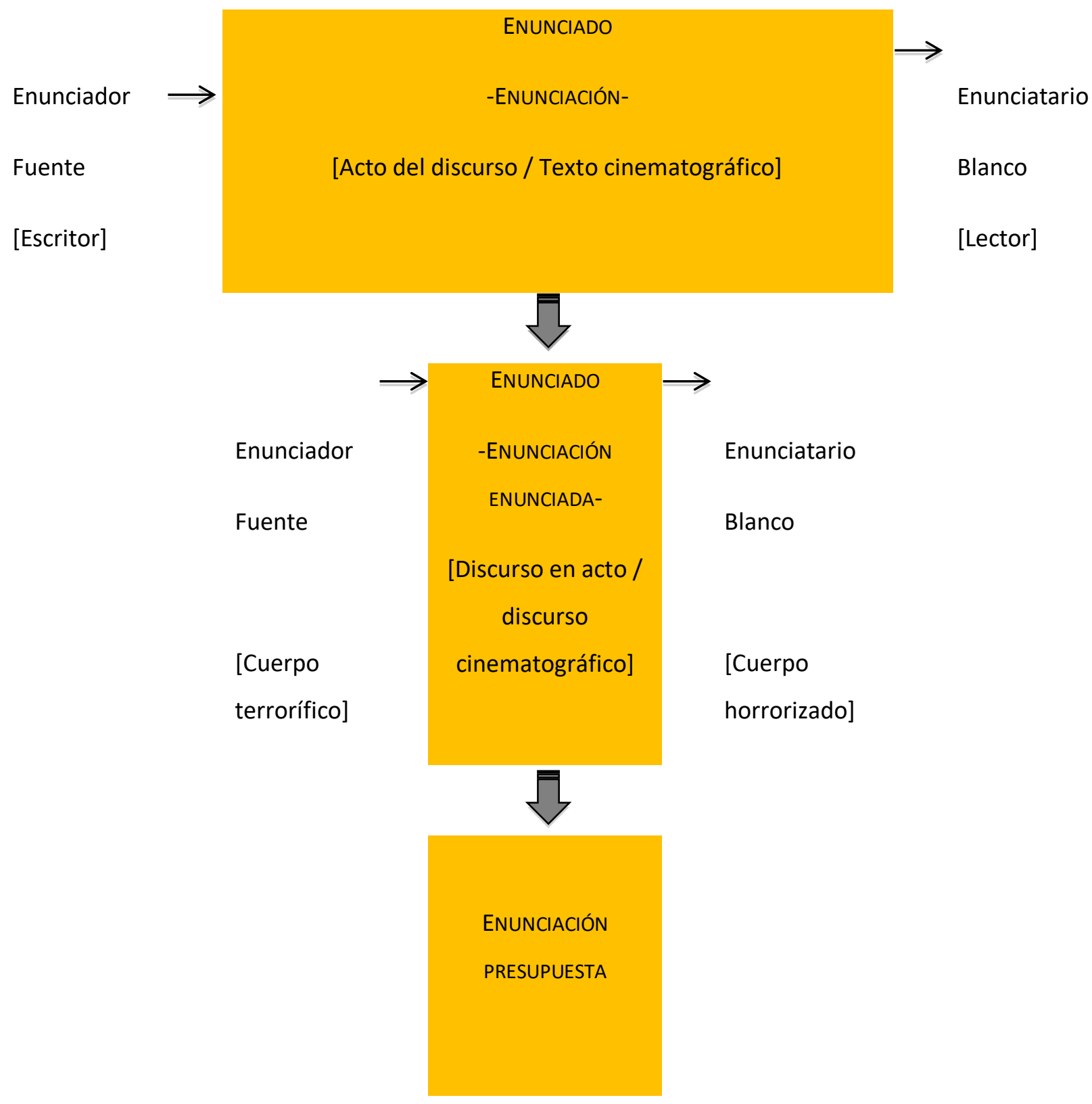




\section{$\sqrt{5}$ \\ Principios \\ semióticos \\ configurantes.}

Si dejamos de lado a la Persona empírica y solo ponemos atención al Mundo posible cinematográfico, es decir, al ENUNCIADO dentro del ENUNCIADO -enunciación enunciada- se observa la presencia de la segunda figura, o sea, el SUJETO IMPLícITO, este funge como centro y vector de la significación, pues deviene en cuerpo. La construcción anterior permite conformar la sintaxis discursiva figurativa, por tanto, la posibilidad de describir las figuras discursivas del cuerpo terrorífico.

El enunciador representa la fuente de donde emanan los discursos, en cambio, el enunciatario es quien recibe el discurso, por tanto, representa al blanco. El sentido toma dirección de la fuente al blanco, sin embargo, es en el discurso en acto donde se encuentran los principios, las normas, los filtros culturales, sociales e históricos con los que se configura el significado. La sintaxis discursiva figurativa, como estrategia de configuración, delimita las posiciones discursivas a las que Fontanille $(2001,2008)$ Ilama actantes de posición -Fuente, Blanco, Control-. No obstante, las figuras discursivas solo son instauradas por un cuerpo vivo. La enunciación presupuesta va un paso más allá de lo lingüístico y lo semántico, se instaura en los presupuestos semióticos. El lector, es evidente, se ve obligado a imaginar una instancia que escapa al acto discursivo y va hacia el discurso en acto, es decir, se trata de la asunción de posiciones percepto-enunciativas inaprensibles solamente por las "personas lingüísticas", pero si fundadoras de modos de existencia.

En la enunciación, ya alejada del centro-ego, aparecerán grados de presencia, es decir, esas presentificaciones, incluso, represenciaciones que permiten analizar la existencia y con ello los modos de existencia semiótica. Se está ante la construcción de los modos de vida, pues el percepto-enunciador revela un mundo, inesperado, sorpresivo y significante; un mundo epifánico inmerso y funcionado con el mundo de los todos los días; ese mundo de las normas, de las regulaciones y, por qué no, de la sospecha. En el mundo 
cotidiano existen cuerpos que perciben y sienten y son afectados por la realidad. Mientras alguien percibe y es afectado por el horror, otro lleva como marcas -intencionales o no- esas figuraciones de lo terrorífico. De tal manera que las figuras discursivas del cuerpo terrorífico inciden en la dimensión de la persona, la cual se explora desde: (a) La forma personal, es decir la persona en relación con el ego-cuerpo; (b) mediante la forma interpersonal o de relación con el otro y (c) a través del uso colectivo de la persona o transpersonalidad. Todas inciden en la figuración de lo horrendo a partir de las envolturas corporales -la piel, los movimientos, tanto del cuerpo horrible hacia el cuerpo aterrado y viceversa. En otras palabras, el lenguaje figurante de lo horrísono es captado por un cuerpo blanco o cuerpo receptor-; en cambio, el cuerpo terrorífico -cuerpo fuente o cuerpo emisor- ha sido figurado como un cuerpo anormal, amorfo o amoral. Sin dejar de lado al cuerpo de control; este refiere a los principios culturales y sociales que permiten trazar la red figurativa pertinente, tanto del cuerpo terrorífico como al cuerpo aterrado.

\section{Figuras discursivas del cuerpo terrorífico}

El cine de horror pone a prueba la egológica de la enunciación, pues los enunciadores no son individuos lingüísticos, sino presencias sensibles, por tanto, la enunciación centralizada en el sujeto queda rebasada. De tal manera, los sujetos dejan de ser meras «predicaciones» para transformase en personas percibientes $y$ sentientes. En tal sentido, las «posiciones enunciativas» son abandonadas constantemente y lo que un momento fungió como enunciador, después será enunciatario o, en última instancia, un él que funciona como filtro, norma o principio de las significaciones discursivas, incluso, podría asumir la posición enunciadora. Como no son individuos lingüísticos, la sintaxis será la de una figuración donde los praxemas, los patemas e incluso los corporemas aproximan a la Semiótica a la significación corporal, por tanto, a los dispositivos semióticos del cuerpo terrorífico. Es por ello que la sintaxis discursiva figurativa del cuerpo terrífico se fundamenta en la enunciación enunciada y en la enunciación presupuesta, para ello baste el siguiente modelo de operación semiótica:

\begin{tabular}{ll|ll} 
CUERPO & ENUNCIADO \\
TERRORÍFICO & -ENUNCIACIÓN \\
ENUENTe] & CUERPO \\
HORRORIZADO & \\
& [Blanco]
\end{tabular}




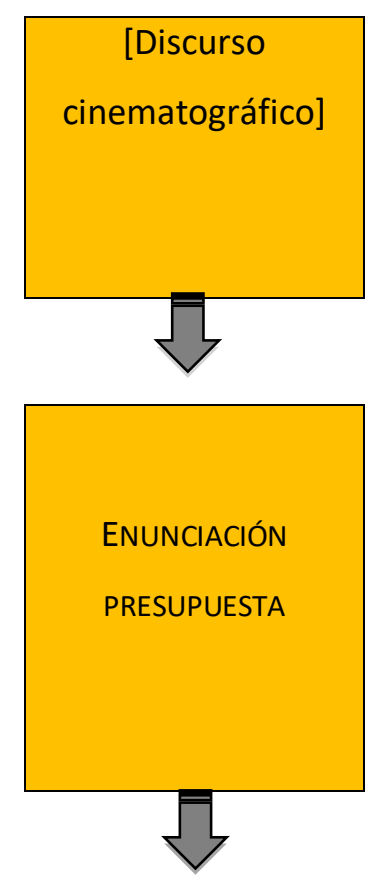

Principios

configurantes

[Control]

Es evidente que los cuerpos [terrorífico y horrorizado] han sido figurativizados, pero lo que interesa es la construcción de las figuras que cada uno asume, así como los principios configurantes. Por ejemplo, un "no viviente, zombi" es percibido por el CUERPO HORRORIZADO como un CUERPO TERRORífICO, cada uno de ellos construyen figuras como "el miedo", "el pasmo" o "la huida" si es un cuerpo blanco. En cambio, si es el cuerpo fuente, la figura principal es la de un muerto-vivo. Los principios configurantes del cuerpo terrorífico instauran otras figuras y principios configurantes: (a) Un cuerpo sin vida, pero en movimiento y (b) la ruptura de las leyes naturales, por tanto, el zombi es anti-natura. De tal manera que se crean figuras, por un lado, de 
lo terrorífico; y por otro, del horror, lo cual permite la configuración de la monstruosidad como represenciación de la degradación de la vida humana. La axiología que resulta de la figurativización del cuerpo horrísono es la de un cuerpo terrorífico y malvado, la de un ser horrendo provocador de miedo.

El miedo, además de estar representado en el cuerpo horrorizado, será proyectado hacia el espectador, pues este tiene la sensación de ser perseguido por el cuerpo horrífico. Por tal motivo, el cine de horror hace que los patemas -miedo- generen corporemas tales como el sobresalto, el nerviosismo o el estar al "filo de la butaca". Pero esto sería un problema de investigación para una percepto-enunciación aplicada el espectador. Por lo pronto, solo para ejemplificar las figuras discursivas instauradas en el ejemplo que nos ocupa tendríamos:

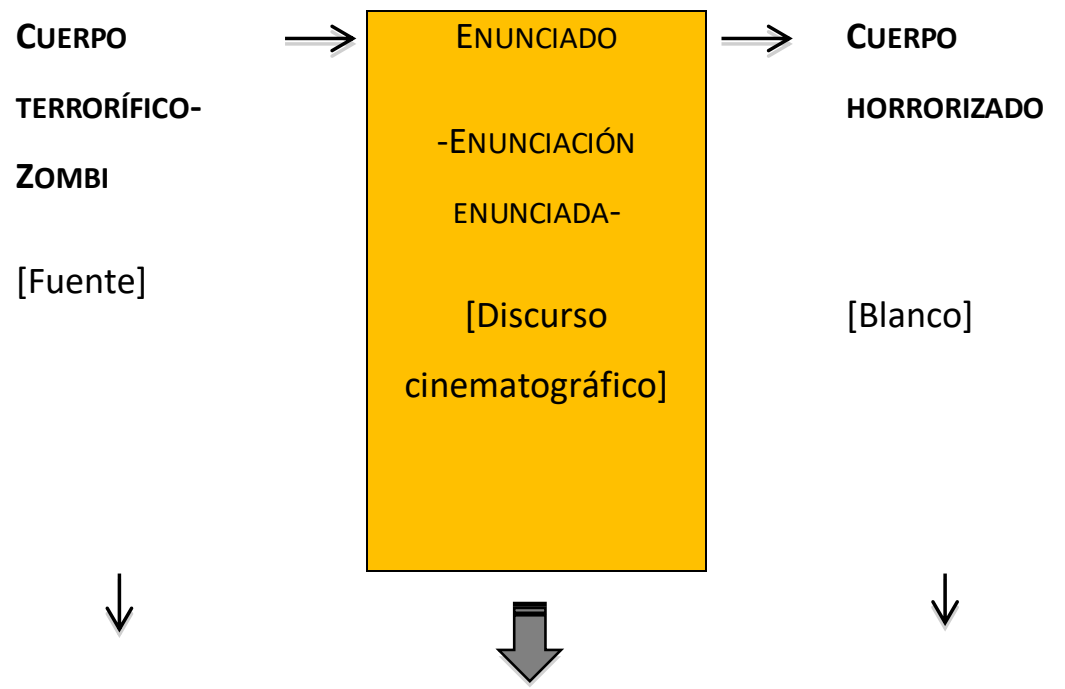

FIGURAS

\begin{tabular}{l} 
ENUNCIACIÓN \\
PRESUPUESTA \\
\hline
\end{tabular}

Figura 1:

Muerto-

Principios

config|urantes
FIGURAS

Figura 1:

Miedo.

Figura 2:

Pasmo. 


\section{Anti-natura.}

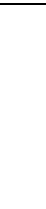

Figura 1:

Zombi-

monstrosidad.

Va en contra de los

principios de la

naturaleza; es anti-

natural.

\section{Figura 3:}

La huida. 
configurante. Si pensamos en la historia del cine, seguramente el primer ser monstruoso que aparece es Nosferatu, el vampiro (1922) de Friedrich Wilhelm Plumpe -Marnau-, fundador del cine de horror alemán. Veamos la sintaxis discursiva figurativa de este personaje horrendo:

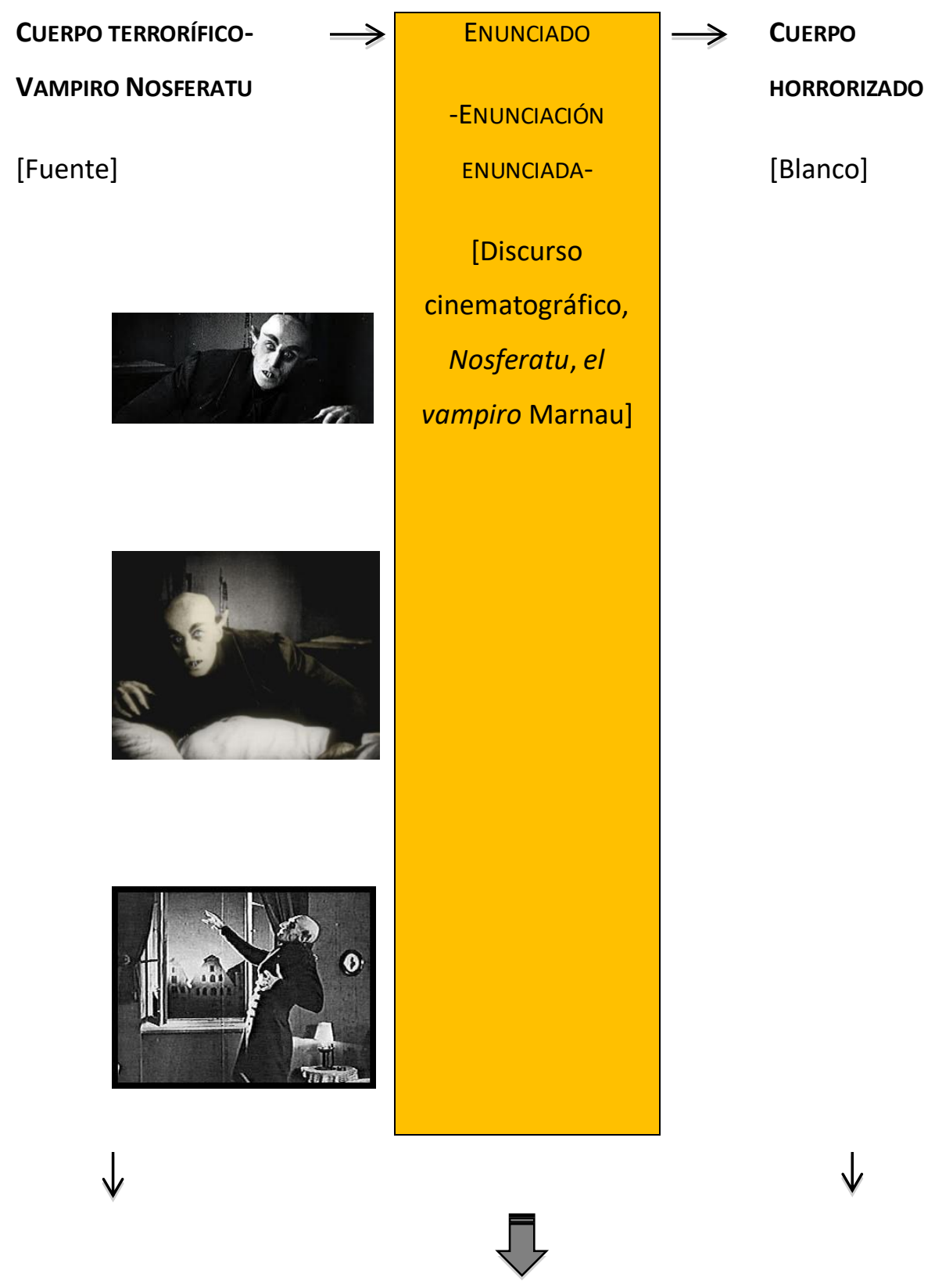


FIGURAS

Figura 1:

Conde Orlock.

Figura 2:

Orejas semejantes a

las de un murciélago.

Figura 3:

Uñas como garras.

Figura 4:

Colmillos al centro de

la dentadura.

Figura 5:

Cuerpo deformado.

\begin{tabular}{|l|}
\hline ENUNCIACIÓN \\
PRESUPUESTA
\end{tabular}

Principios

configurantes

Figura 1:

Antinatural.

Figura 2: Personaje

al acecho.

Figura 3:

Cielo. Ennegrecido.

Figura 4:

Involución.

Figura 5:

Solitario.

Figura 6:
FIgURAS

Figura 1:

Miedo.

Figura 2:

Horror.

Figura 3:

El temor. 
Marginal.

Figura 7:

El sigilo.

Figura 9:

Alimentarse de

sangre humana.

Es evidente que el horror implicaría muchas otras figuras, la cuales están relacionadas con el pavor, la incomodidad, la repugnancia, además de las ya mencionadas. Incluso en los principios configurantes también inciden núcleos semánticos como la anormalidad; los personajes de naturaleza maligna como los criminales; lo sobrenatural como en el caso de los vampiros o lo repugnante que resulta de alimentarse de sangre humana. No obstante, lo que interesa es delimitar las figuras discursivas del cuerpo horrífico.

Las manifestaciones afectivas siempre provocan una reacción somática. Ya se mencionó el pasmo o la huida, pero también pueden, en el cuerpo horrorizado aparecer el asco y el vómito. Es bueno aclarar que el cine de horror ha recurrido múltiples veces a la literatura, a los cuentos de terror, a las leyendas e incluso a la oralidad. Otra recurrencia son los imaginarios sociales donde aparece el temor a lo sobrenatural y a lo desconocido. Entonces la realidad se transforma en una pesadilla, por eso:

No es coincidencia que las figuras más populares en el cine de horror sean figuras abominables que carecen de alma y habitan cuerpos descompuestos. Dentro de estas figuras encontramos vampiros $u$ hombres lobo (cuerpos mitad humano- mitad animal, inmortales, pero sin alma), zombis (muertos vivientes), demonios (ángeles caídos), fantasmas (almas en pena), momias (cuerpos descompuestos), etc. (Cuéllar Barao, 2008, p. 235).

Se trata de monstruos de la noche que han nacido de contextos socioculturales diversos. Es claro que el vampiro, el hombre lobo, las brujas, entre otros seres que, por lo general, se tipifican como horrendos. En 
otras palabras, la fealdad, ya sea la desproporción física; ya sea lo desagradable en el plano de la moral es la causante del terror. Sin olvidar lo deforme corporal congénito, pues como va en contra del orden natural, también provoca horror. Por tanto, debe considerarse que las construcciones significativas subyacen en todo aquello que la sociedad estima como aberrante, malsano o fuera de la lógica de la vida social.

Los monstruos son considerados feos y horrendos, en tal sentido representan la maldad. Tal como sucede con personajes como Bestia (La bella y la bestia), Frankenstein o el jorobado de Notre-Dame, personajes físicamente horrendos, pero bondadosos. No obstante, la sociedad los rechaza por su fealdad, de tal manera que fueron obligados a actuar en contra de las normas sociales con acciones abominables como el asesinato. Las reconfiguraciones de los personajes míticos de horror se encuentran entre las fronteras de la belleza y de la fealdad, tal como ha ocurrido con Drácula (1992) de Francis Ford Coppola. Un vampiro seductor, pero a la vez, un ser horrendo, veamos la construcción de la sintaxis discursiva figurativa:

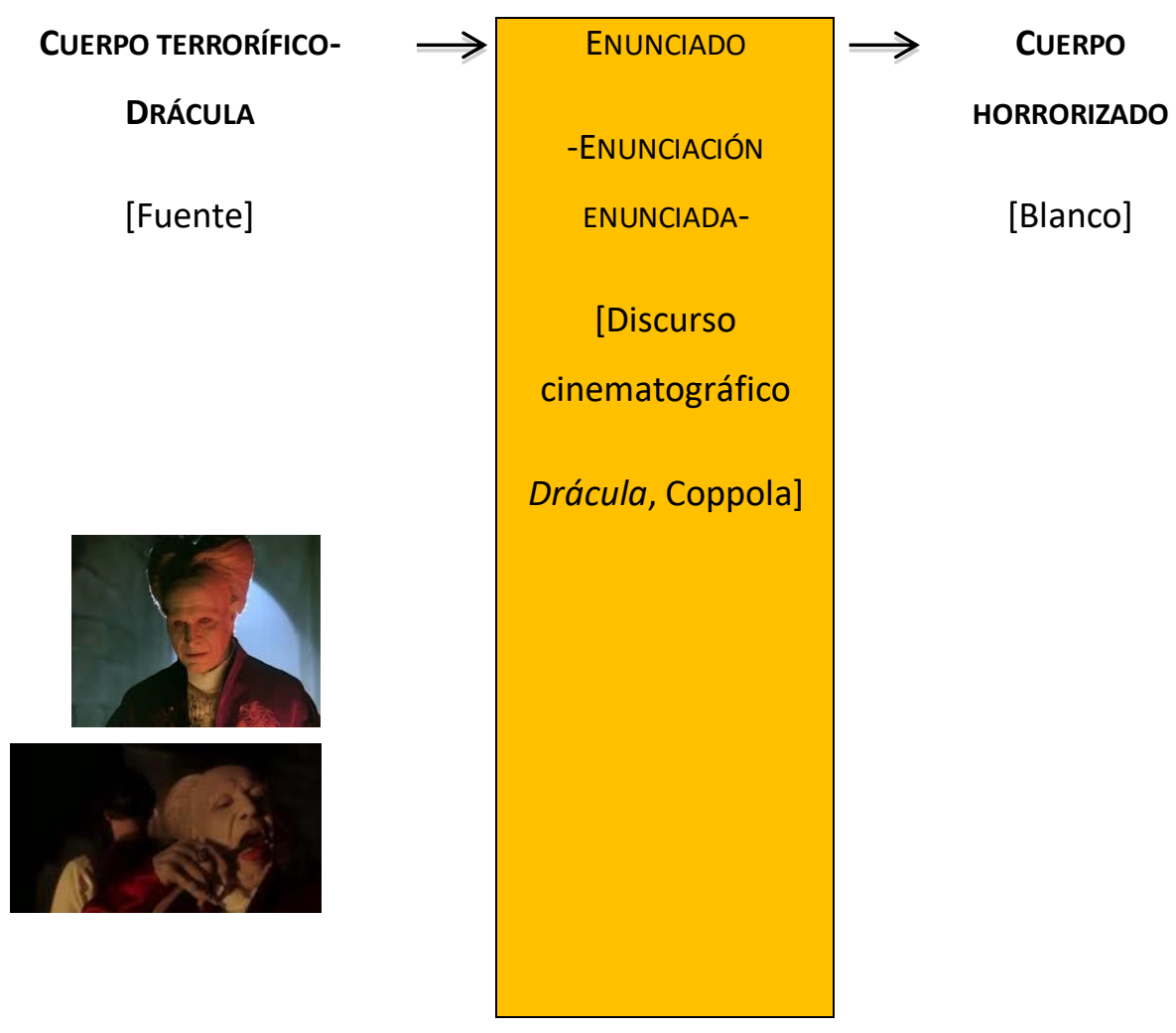




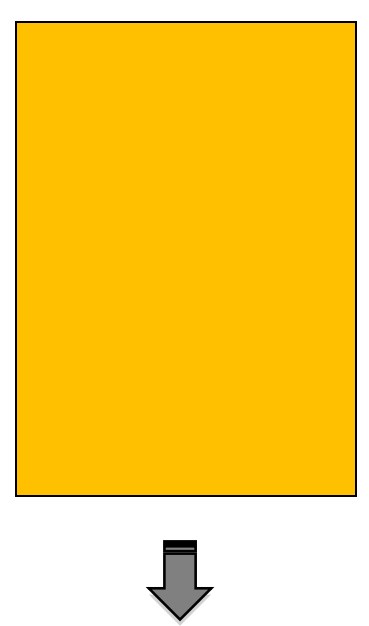

FIGURAS

Figura 1:

Muerto-viviente.

\section{Figura 2:}

Anti-natura.

Figura 3:

Uñas largas.

\section{Figura 4:}

Comer sangre.

Figura 5:

Dientes incisivos

grandes.

ENUNCIACIÓN
PRESUPUESTA

Principios

Configurantes

Figura 1:

Antinatural.

Figura 2:

Personaj

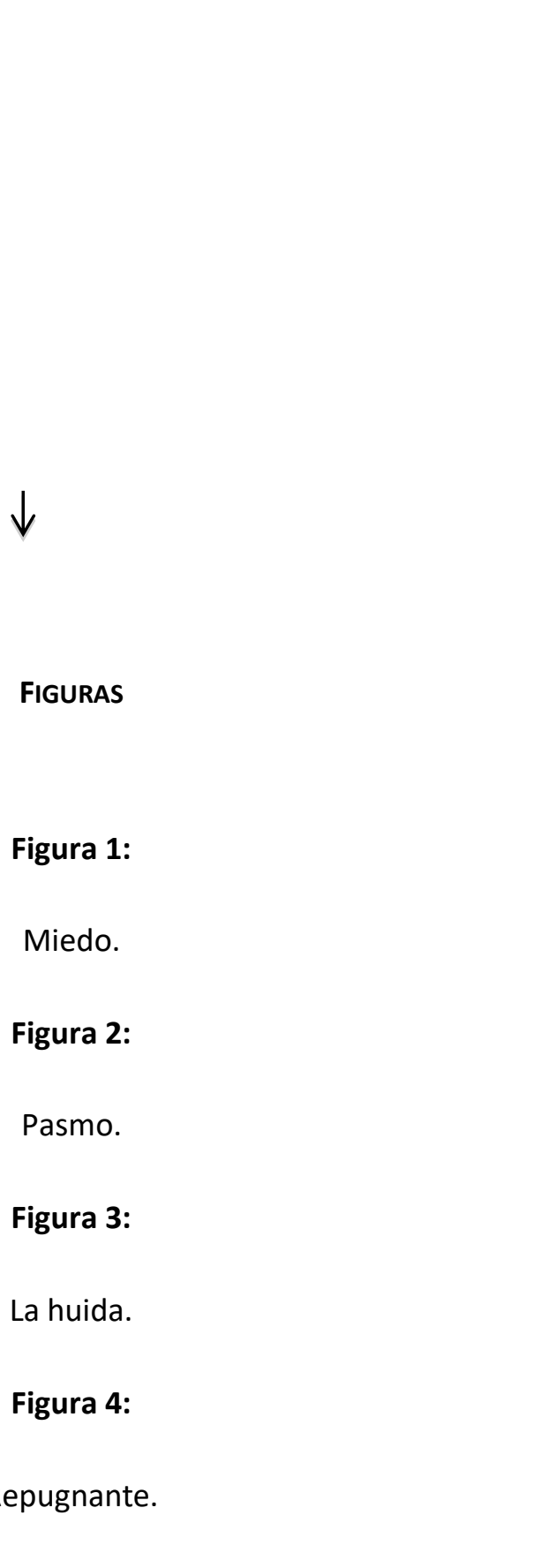

FIGURAS

Figura 1:

Miedo.

\section{Figura 2:}

Pasmo.

Figura 3:

La huida.

\section{Figura 4:}

Repugnante.
Figura 5:

Angustia. 
Figura 6:

Degradación

corporal.

Figura 5:

Deformación de la

belleza

(tanto física como

moral). seductor.

\section{Figura 3:}

Atmósferas

oscuras.

\section{Figura 4:}

Plaga de ratas.

\section{Figura 5:}

Alimentarse de

sangre humana.

\section{Figura 6:}

Religión: oposición

a Dios.

\section{Figura 7:}

Venganza.

\section{Figura 8:}

Tiniebla /Niebla.

\section{Figura 9:}

Control del mundo

natural

(tormentas). 
Otros elementos en la trasformación de la figura mítica de vampiro son: (a) emprender la venganza en contra de Dios y (b) la pérdida de la fe del personaje lo vuelve invulnerable a los crucifijos y al agua bendita, aunque es vulnerable a la luz del día. Es importante notar cómo la oscuridad, la luna roja, la penumbra y el control de la naturaleza acentúan el sentimiento de angustia y miedo en el cuerpo horrorizado. No solo las figuras corporales del cuerpo horrísono inciden en la semiótica del terror, también las atmósferas oscuras como la tiniebla o el domino que el personaje tiene sobre el mundo natural como el dominio del clima y el control de la plaga de ratas, por ejemplo. Figuras de lo sobrenatural que inciden en la intensificación de lo horrido.

El horror alude entre muchas otras posibilidades a la ruptura de las fronteras entre lo aceptado y lo no aceptado. Traspasar los límites significa arriesgar la vida o lo que es más importante, eso que las sociedades llaman alma, espíritu, libertad, capacidad de decisión, etcétera. Los resultados también pueden ser diversos como la pérdida de la razón o simplemente transformarse en un ser poseído; en un ser aberrante tal como ocurre con El proyecto de la bruja de Blair (1999) de Myrick o El resplandor (1980) de Stanley Kubrick, donde no solo se pasan las fronteras entre lo normal y lo aberrante. En cambio, lo monstruoso puede ser llevado hasta lo grotesco y lo siniestro. Es como un vuelco a lo desagradable, a lo anormal, incluso a lo sobrenatural. Lo grotesco, dice Rafael Gómez Alonso:

Sugiere que la calificación de lo entendido como grotesco hace referencia a lo que se aparta considerablemente de las reglas estéticas corrientes y contiene un elemento material corporal claramente destacado y exagerado, es decir, la estética de lo grotesco es la estética de la deformidad o la monstruosidad y de lo que está del lado de lo anormal y siniestro $(2001$, p. 11$)$.

Ahora bien, lo grotesco se aleja totalmente de las normas estéticas convencionales, pues la corporeidad es deformada al extremo. Sin lugar a dudas, la exageración de la anormalidad corporal llega a lo monstruoso y lo siniestro, como la desfiguración total del rostro. Así mismo, la maldad, lo 
sobrenatural y la maldad extrema llegan la ofensa, a la afrenta y a la injuria de todo aquello normado socialmente. Elementos que colocan al cuerpo horrorizado entre la angustia y el pasmo.

La fealdad extrema, lo grotesco y lo siniestro figuran a un cuerpo terrorífico alejado de todo lo conocido. Por tanto, se acentúa el miedo, el horror y la angustia a tal grado que el espectador es colocado en los márgenes de todo lo conocido. El cuerpo horrendo, aunado a lo siniestro y lo sobrenatural, lleva al espectador a imaginar y sentir lo que no se ha sentido. Además, lo siniestro coloca al cuerpo horrísono en la figuración de lo no visto y lo no deseable, tal como ocurre con EI exorcista (1975) donde William Friedkin pone énfasis en los imaginarios inaceptables. Las figuras de las de la degradación corporal del texto de Friedkin se exponen con la siguiente sintaxis discursiva figurativa:

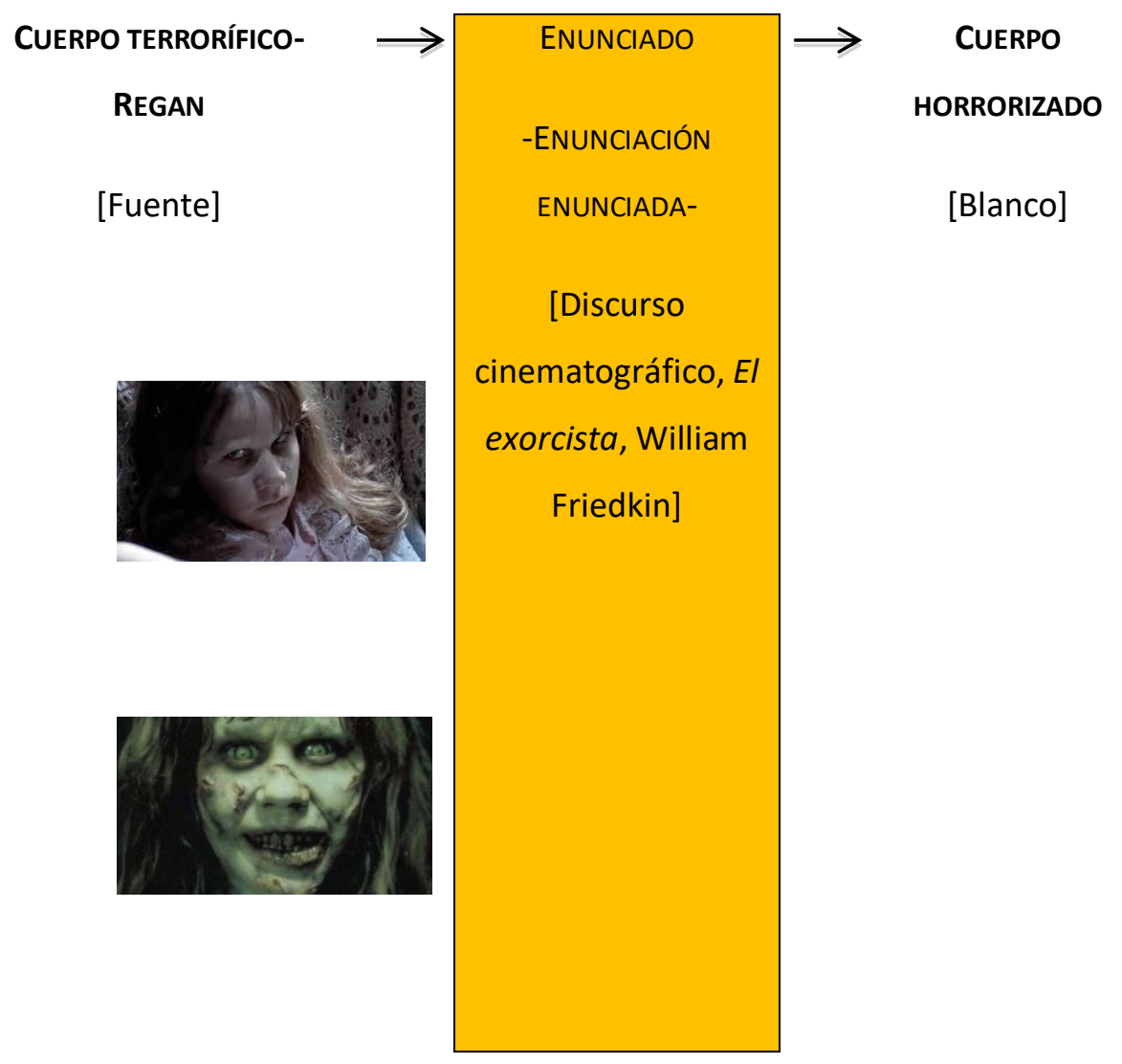



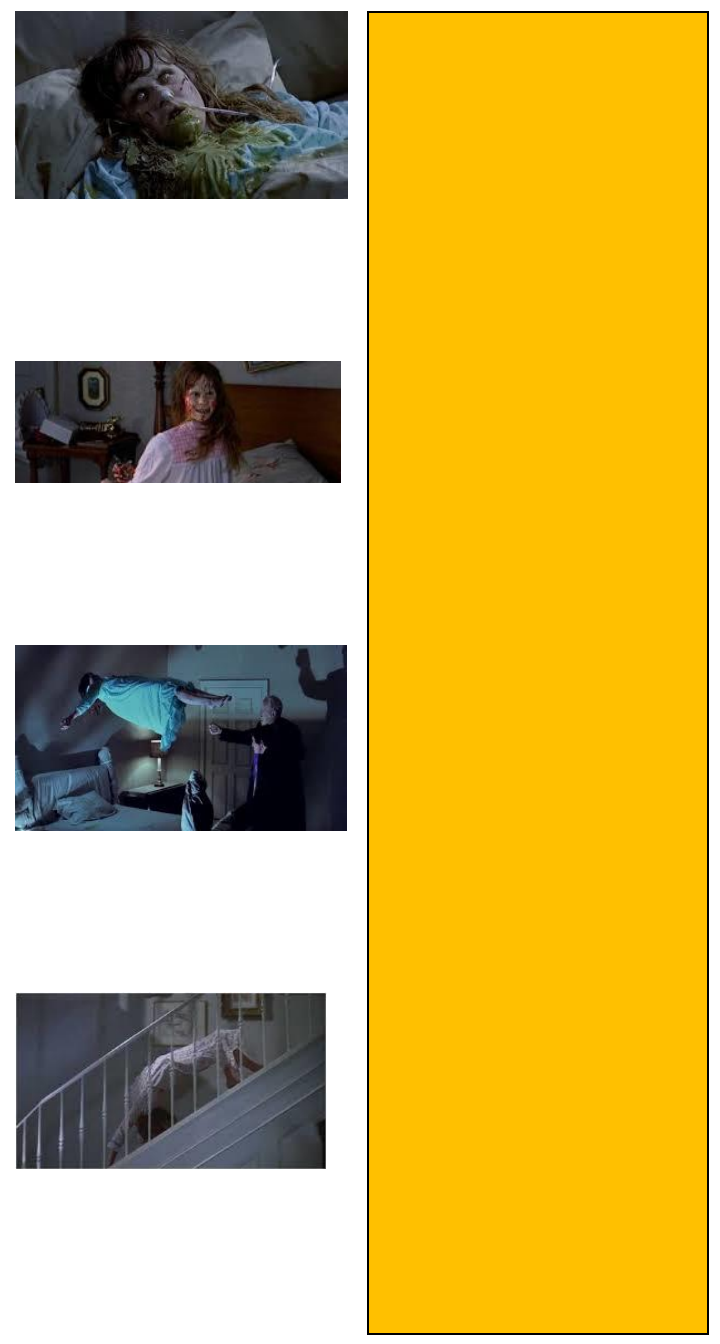

$\downarrow$

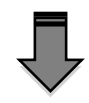

$\downarrow$

FIGURAS

\begin{tabular}{l} 
ENUNCIACIÓN \\
PRESUPUESTA \\
\hline
\end{tabular}

Figura 1:

Degradación

Principios

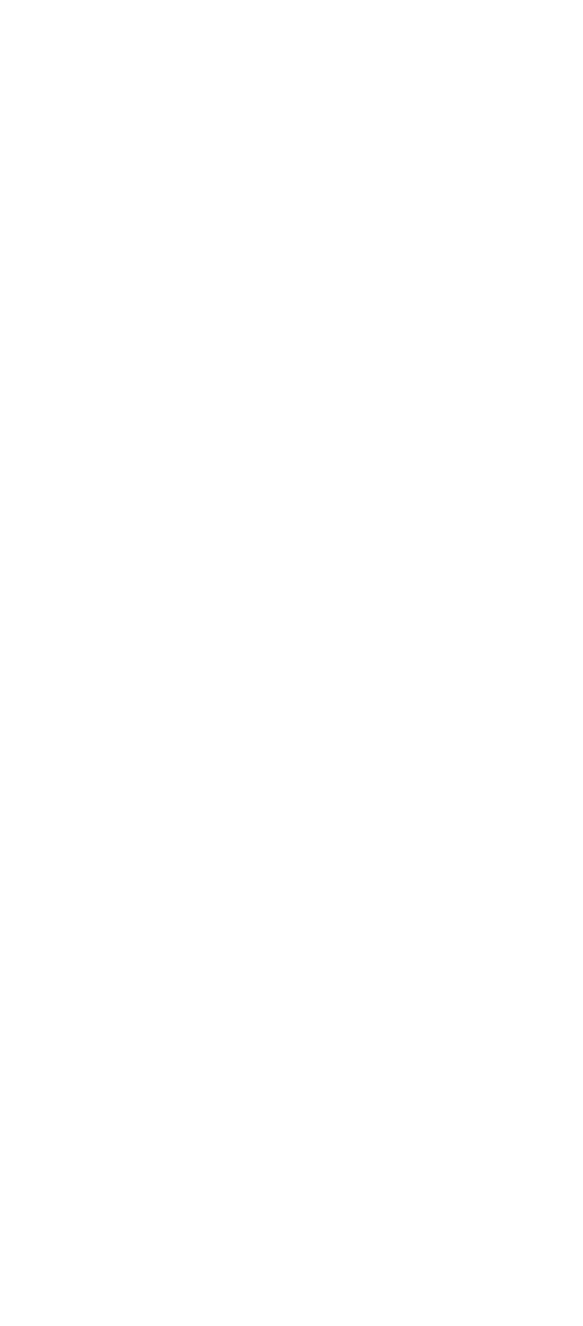

FIGURAS

Figura 1:

Miedo. 
corporal.

Figura 2:

La supuración.

\section{Figura 3:}

El vómito: expulsión de sangre y fluidos verdes, viscosos y desagradables.

Figura 4:

Cambio de personalidad.

\section{Figura 5:}

Excreción

corporal: orina.

Figura 6:

Espasmos y

contorsiones

corporales.

\section{Figura 7:}

Ojos en blanco.

\section{Figura 9:}

Cuello abultado. configurantes

Figura 1:

La posesión

demoníaca de una

niña.

\section{Figura 2:}

Antinatural.

Figura 3:

Ruptura de todas

las normas

naturales y

sociales.

Figura 4:

Lo no humano.

\section{Figura 5:}

Negación de la
Figura 2:

Horror.

Figura 3:

El temor.

\section{Figura 4:}

La repulsión.

Figura 5:

Huida. 
Figura 10:

Posturas corporales

imposibles en el

mundo natural como

girar la cabeza

alrededor del cuello.

\section{Figura 11:}

La torsión del cuerpo

totalmente arqueado

y descenso por las

escaleras de forma

antinatural.

\section{Figura 12:}

Deformación total

del rostro.

Figura 13:

Arrebato de la voz

humana.

Figura 14:

Voz monstruosa.

Figura 15:

\section{Poderes}

sobrenaturales:

\section{ayuda}

(cuando el cuerpo

de Regan ha

sufrido la

deformación total

y con una voz

monstruosa dice: -

“iAyúdame!”).

\section{.}




\section{El cuerpo se eleva}

sobra la cama.

El espectador es llevado a escena, es transformado en un testigo, en un voyerista que pasa del terror psicológico a la desesperación. Antecedentes de esta configuración, por lo menos en el sentido de la posesión demoniaca, ya se encuentran en La semilla del diablo (1968) de Roman Polanski, donde lo visual es lo protagónico, donde la corporalidad ha sido violentada en todos los órdenes humanos y biológicos. El terror, la angustia y el miedo -en El exorcista- acercan al cuerpo horrorizado al borde de la repulsión. La estrategia visual y violenta en extremo, provocan en el espectador cinematográfico la angustia y el horror, lo cual es el recordatorio de su vulnerabilidad.

Los cuerpos corporales deformes, lo monstruoso y la confrontación con lo sobre natural causa terror, no solo Nosferatu, o el hombre lobo, sino también las actividades humanas consideradas obscenas, impulsivas y aberrantes. Aún más, lo horrífico también está implicado en lo creado por el hombre al traspasar el umbral de lo prohibido. De tal manera que el ser horrendo ya no es solo una sombra o un fantasma, sino aquellos cuerpos horríficos extraños que invaden el cuerpo de los demás con la finalidad de perpetuar su vida, aunque destruyan la vida humana. Así sucede cuando los habitantes de las Torres Starliner se enfrentan a un parásito que violenta los cuerpos. Se trata, sin lugar a dudas, de la narración expuesta en Vinieron de dentro... (1975) de David Cronenberg, obsérvese la sintaxis discursiva figurativa: 


\section{CUERPO TERRORÍFICO- \\ PARÁSITO, CREADO $\longrightarrow$ POR HOBBES}

[Fuente]
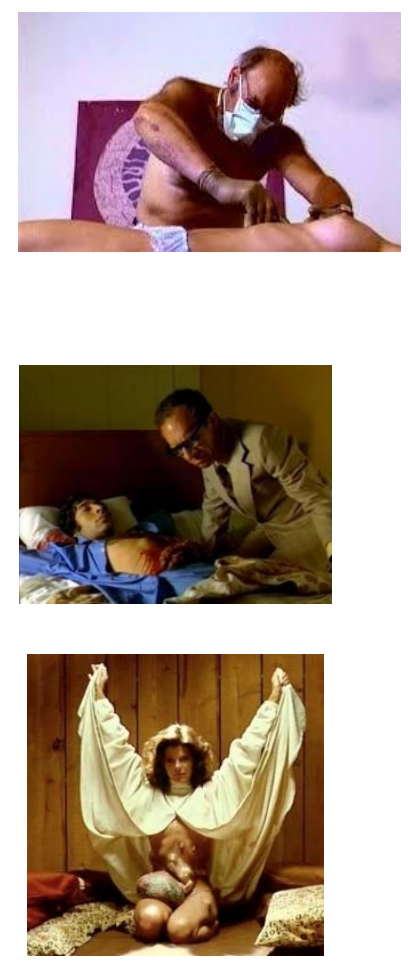

$\downarrow$

FIGURAS

Figura 1:

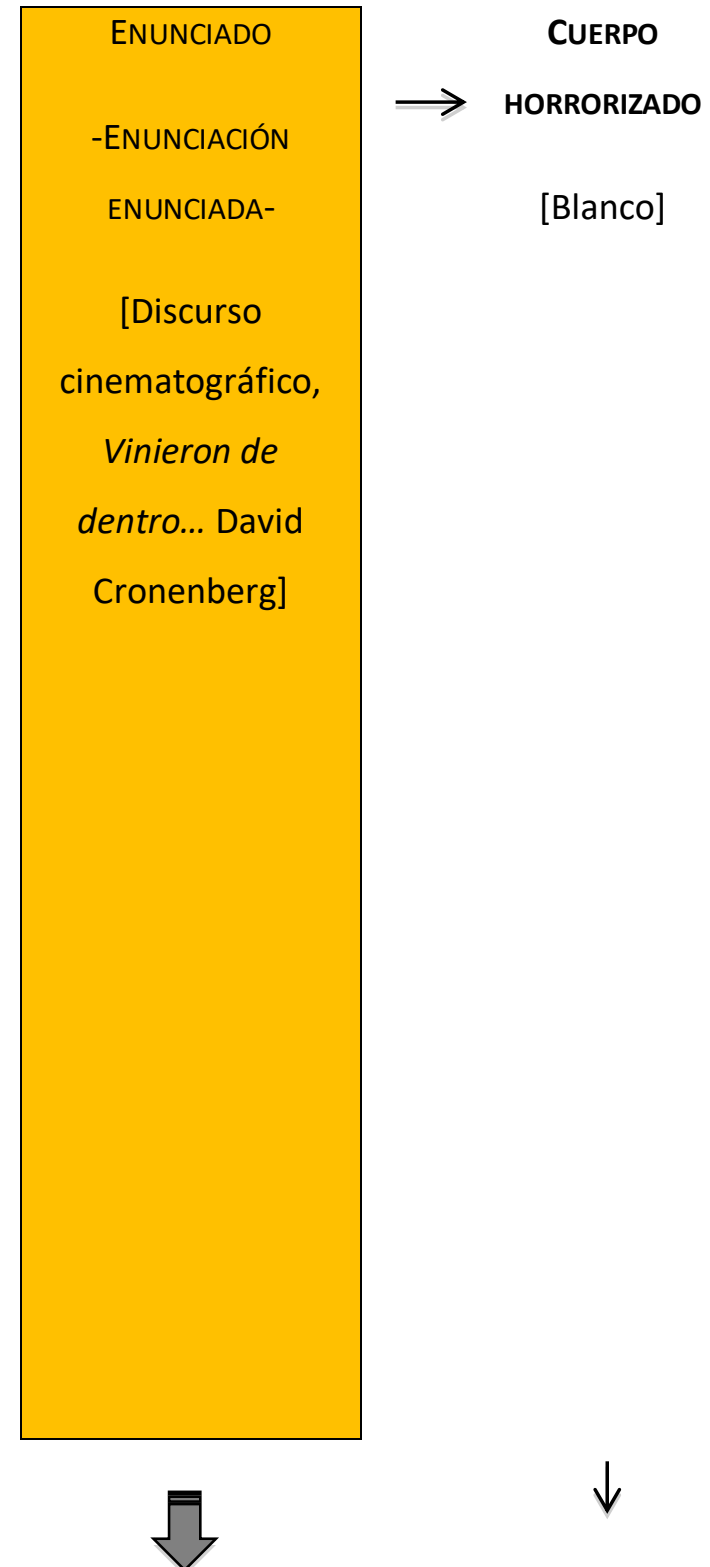

FIGURAS

Figura 1: 
Parásito creado

genéticamente.

Figura 2:

Parásito sanguinario.

Figura 3:

Una mujer joven es

portadora del parásito.

\section{Figura 4:}

Hobbes ha creado el

parásito.

\section{Figura 5:}

El parásito realiza

violaciones corporales.

Figura 6:

El parásito abandona los cuerpos de las víctimas por la boca.

\section{Figura 7:}

Vómito cárnico vivo (el parásito).

Figura 8:

Vómito de sangre

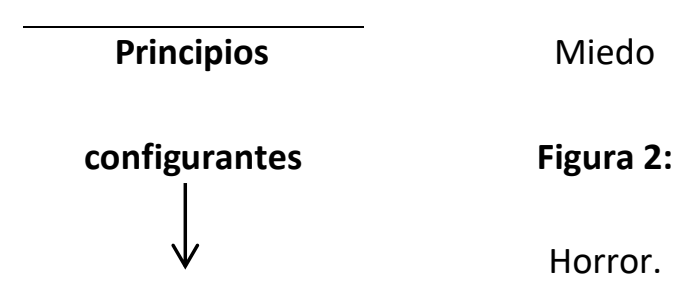

\section{Figura 3:}

El temor.

\section{Figura 4:}

Figura 1:

Hobbes

La violación por

parte del parásito a

los habitantes.

\section{Figura 2:}

El parásito

abandona el

cuerpo de las

víctimas e invade

el espacio social.

\section{Figura 3:}

Invasión de los

cuerpos de los

habitantes

(se introduce por

la vagina). destruye al

parásito.

Figura 5:

El suicidio de

Hobbes.

Figura 6:

Hobbes ha

sido

contaminado

por el

parásito. 


\author{
acompañado del \\ parásito.
}

Figura 4:

Invasión del

espacio social y

corporal.

\section{Figura 5:}

La sexualidad

aberrante.

El cuerpo, antes de ser horrizado, entra en tensión con el mundo natural, pues es violentado por el cuerpo extraño. El cuerpo horrífico es acompañado por la sangre que brota por los orificios corporales, de tal forma que

Lo más interesante sigue siendo referenciar y medir el sentimiento de horror frente a la escena sangrienta. Entendemos por esta expresión la rebelión del ser que provoca un sentimiento, más o menos fugitivo, de desolidarización y que convierte la masacre en espectáculo; la conciencia y el rechazo, estrechamente relacionados, de la proximidad con el animal y el monstruo; el descubrimiento terrorífico de la virtualidad innoble en sí" (Corbin, 2005, p. 206).

Hobbes ha aplicado la ingeniería genética para crear al parásito -especie de babosa- que invade los cuerpos, tanto los sociales -Torres Starliner- como los corporales de cada uno de los habitantes de la torre. En consecuencia, cuando las personas son "penetradas" por el parásito se convierten en seres sexualmente insaciables y terminan por convertirse en asesinos. Las actividades del ser humano, alejadas de la moral social como la sexualidad aberrante son figuras semióticas de lo grotesco, en tal sentido producen horror. El cuerpo horrorizado, en el caso de la película de Cronenberg, no solo el cuerpo blanco, sino que la actividad anormal humana se vuelve en contra del hombre mismo.

La transferencia corporal, en especial de un cuerpo horrísono a un cuerpo considerado normal, quiebra lo considerado civilizado, natural y normal. Más si el cuerpo afectado modifica su corporeidad y 
asume la función del cuerpo horrorizado y lo convierte en abominable, de ahí que el cuerpo afectado sea un cúmulo de emociones disfóricas. La mutación de un cuerpo en otro es un tema recurrente en los mitos humanos, por ejemplo, en el hombre lobo. Sin embargo, David Cronenberg recurrió a la morfogénesis en su texto La mosca (1986), donde Seth Brundle, joven científico, cambia su morfología a la de forma de una mosca. Lo interesante es que la novia de Seth sufre una pesadilla donde dará a luz a una larva de mosca en lugar de un niño. Se trata de un huésped ajeno a la naturaleza humana, tal como sucede con Allien, el octavo pasajero (1979) de Ridley Scott, película de la cual se perfilan las figuras discursivas del cuerpo terrorífico:

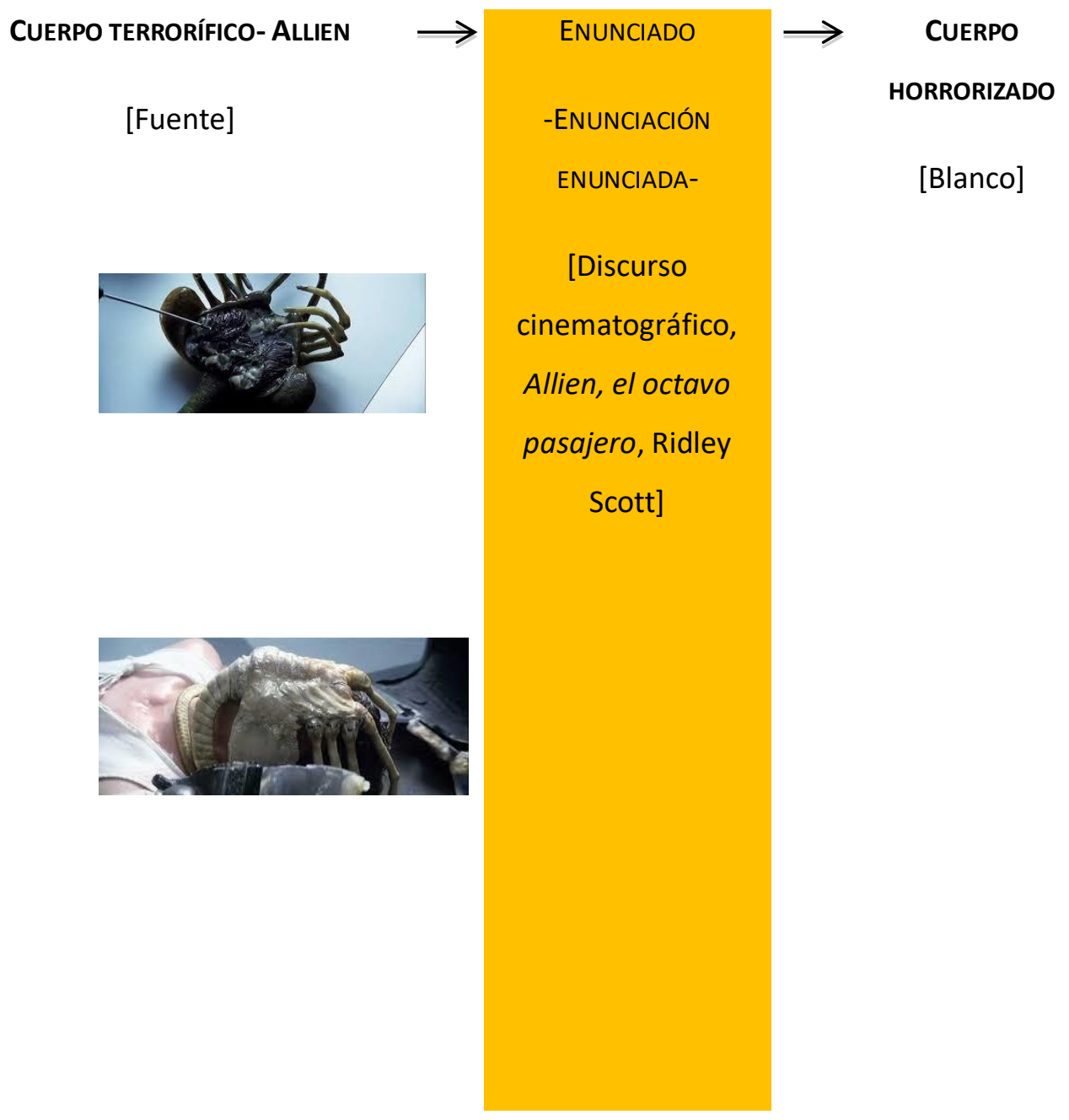



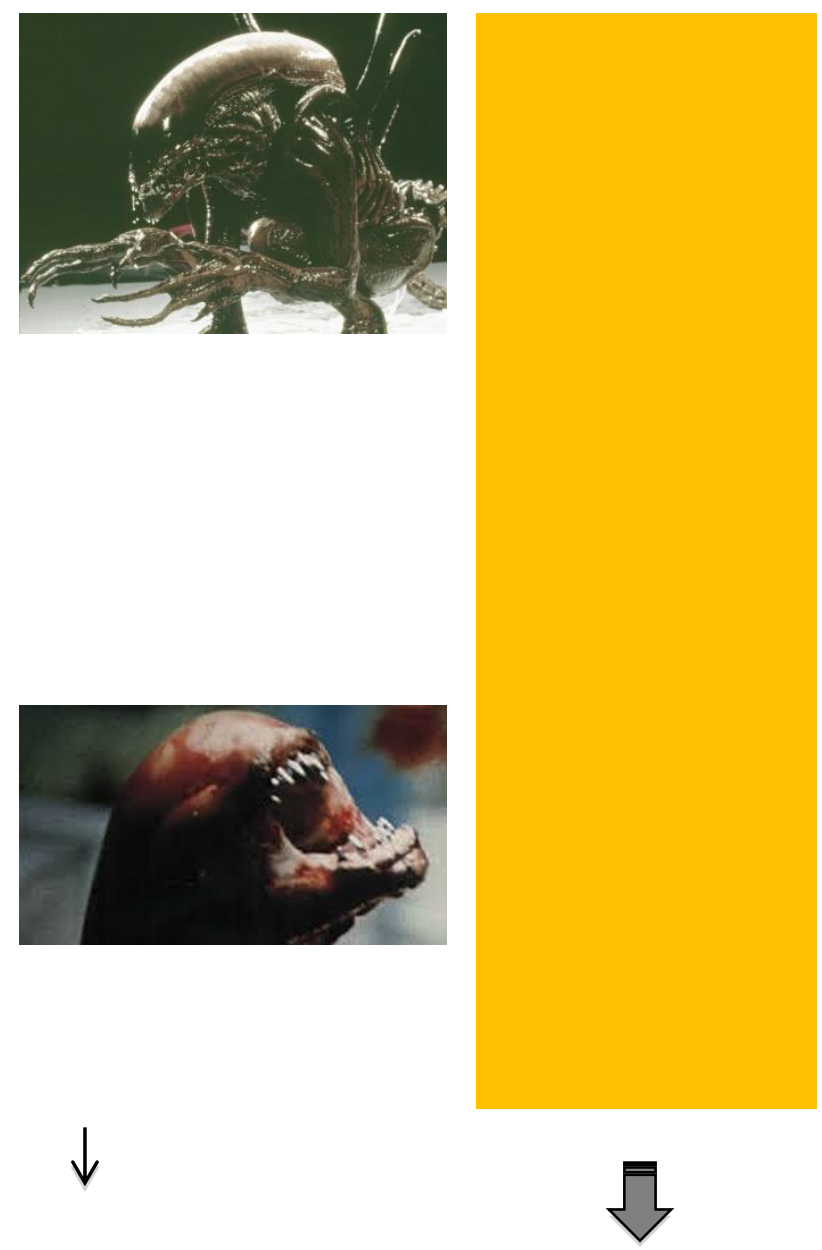

FIGURAS

ENUNCIACIÓN
PRESUPUESTA

Principios

Figura 1:

Ser montuoso.

Figura 2:

Secreciones no humanas configurantes

$\downarrow$ $\downarrow$

FIGURAS

(2)
Figura 1:

Miedo.

\section{Figura 2:}

Horror. 
(ácido).

Figura 3:

Criatura alienígena.

Figura 4:

Caparazón de crustáceo y $\sin$ ojos.

Figura 5:

$$
\begin{gathered}
\text { Nacimiento de un cuerpo } \\
\text { humano que sirve de } \\
\text { nodriza, nace entre vísceras } \\
\text { y sangre humana. }
\end{gathered}
$$

\section{Figura 6:}

Deformación corporal.

\section{Figura 7:}

Incuba huevecillos en los

cuerpos humanos.

\section{Figura 9:}

Sanguinolento y baboso.
Figura 1:

$$
\begin{gathered}
\text { Invasión corporal } \\
\text { por un cuerpo no } \\
\text { humano (la } \\
\text { criatura }
\end{gathered}
$$$$
\text { alienígena). }
$$

\section{Figura 2:}

Fuerza

sobrehumana.

\section{Figura 3:}

$$
\text { Espacio }
$$

interestelar

$$
\text { (espacio no }
$$

humano).

\section{Figura 4:}

Neblina dentro de

$$
\text { la nave }
$$

(Nostromo)

\section{Figura 3:}

El temor.

\section{Figura 4:}

Huida.

\section{Figura 4:}

Temor a ser

fecundado

por el Allien. 


$\begin{array}{ccc}\text { CUERPO TERRORíFICO } & \text { CUERPO DE CONTROL } & \text { CUERPO } \\ \text { [Fuente] } & \text { [Principios } & \text { HORRORIZADO } \\ & \text { Configurantes] } & \text { [Blanco] }\end{array}$

Figura 1: Orejas semejantes a las de un murciélago.

Figura 2: Uñas como garras.

Figura 3: Colmillos al centro de la dentadura.

Figura 4: Cuerpo deformado.

Figura 5: Muerto viviente (vampiro).

Figura 6: Alimentarse de sangre humana.

Figura 7: Dientes incisivos grandes.

Figura 8: Deformación de la belleza

$$
\text { (tanto física como moral). }
$$

Figura 9: La supuración, vómito: expulsión de sangre y fluidos verdes, viscosos y desagradables, excreción corporal.

Figura 10: Cambio de personalidad.

Figura 11: Espasmos y contorsiones corporales, posturas corporales imposibles en el mundo natural: Girar la cabeza alrededor del cuello, ojos en blanco, la torsión del cuerpo totalmente
Figura 1: Antinatural.

Figura 2: Personaje al acecho.

Figura 3: Cielo

ennegrecido.

Figura 4: Involución.

Figura 5: Solitario, marginal.

Figura 6: El sigilo.

Figura 7: Alimentarse de sangre humana.

Figura 8: Personaje seductor.

Figura 9: Atmósferas oscuras.

Figura 10: Domino sobre el clima y sobre la plaga de ratas.

Figura 11: Alimentarse
CUERPO
HORRORIZADO
[Blanco]
Figura 1:
Miedo.
Figura 2:
Horror.
Figura 3: El
temor.
Figura 4:
Pasmo.
Figura 8: El
Femor.
Figura 5: La
huida.
Repugnante.
Angustia.
Figura
Pora

CUERPO
HORRORIZADO
[Blanco]
Figura 1:
Miedo.
Figura 2:
Horror.
Figura 3: El
temor.
Figura 4:
Pasmo.
Figura 8: El
Femor.
Figura 5: La
huida.
Repugnante.
Angustia.
Figura
Pora

CUERPO
HORRORIZADO
[Blanco]
Figura 1:
Miedo.
Figura 2:
Horror.
Figura 3: El
temor.
Figura 4:
Pasmo.
Figura 8: El
Femor.
Figura 5: La
huida.
Repugnante.
Angustia.
Figura
Pora

CUERPO
HORRORIZADO
[Blanco]
Figura 1:
Miedo.
Figura 2:
Horror.
Figura 3: El
temor.
Figura 4:
Pasmo.
Figura 8: El
Femor.
Figura 5: La
huida.
Repugnante.
Angustia.
Figura
Pora

CUERPO
HORRORIZADO
[Blanco]
Figura 1:
Miedo.
Figura 2:
Horror.
Figura 3: El
temor.
Figura 4:
Pigura 8: El
temor.
Figura 7:
Figura 5: La
huida.
Repugnante.

CUERPO
HORRORIZADO
[Blanco]
Figura 1:
Miedo.
Figura 2:
Horror.
Figura 3: El
temor.
Figura 4:
Pasmo.
Figura 8: El
Femor.
Figura 5: La
huida.
Repugnante.
Angustia.
Figura
Pora

CUERPO
HORRORIZADO
[Blanco]
Figura 1:
Miedo.
Figura 2:
Horror.
Figura 3: El
temor.
Figura 4:
Pasmo.
Figura 8: El
Femor.
Figura 5: La
huida.
Repugnante.
Angustia.
Figura
Pora

CUERPO
HORRORIZADO
[Blanco]
Figura 1:
Miedo.
Figura 2:
Horror.
Figura 3: El
temor.
Figura 4:
Pasmo.
Figura 8: El
Femor.
Figura 5: La
huida.
Repugnante.
Angustia.
Figura
Pora

CUERPO
HORRORIZADO
[Blanco]
Figura 1:
Miedo.
Figura 2:
Horror.
Figura 3: El
temor.
Figura 4:
Pasmo.
temor.
Figura 8: El
Rigura 6:
huida.

CUERPO
HORRORIZADO
[Blanco]
Figura 1:
Miedo.
Figura 2:
Horror.
Figura 3: El
temor.
Figura 4:
Pasmo.
Figura 8: El
Femor.
Figura 5: La
huida.
Repugnante.
Angustia.
Figura
Pora

CUERPO
HORRORIZADO
[Blanco]
Figura 1:
Miedo.
Figura 2:
Horror.
Figura 3: El
temor.
Figura 4:
Pasmo.
temor.
Figura 7:
higura 5: La
Repuida.

CUERPO
HORRORIZADO
[Blanco]
Figura 1:
Miedo.
Figura 2:
Horror.
Figura 3: El
temor.
Figura 4:
Figura 8: El
temor.
Pasmo.
Figura 6:
huigura 5: La

CUERPO
HORRORIZADO
[Blanco]
Figura 1:
Miedo.
Figura 2:
Horror.
Figura 3: El
temor.
Figura 4:
Pasmo.
Figura 8: El
Femor.
Figura 5: La
huida.
Repugnante.
Angustia.
Figura
Pora

CUERPO
HORRORIZADO
[Blanco]
Figura 1:
Miedo.
Figura 2:
Horror.
Figura 3: El
temor.
Figura 4:
Pasmo.
temor.
Figura 7:
higura 6:
Repugnante.

CUERPO
HORRORIZADO
[Blanco]
Figura 1:
Miedo.
Figura 2:
Horror.
Figura 3: El
temor.
Figura 4:
Pigura 8: El
temor.
Figura 7:
Figura 5: La
huida.
Repugnante.

CUERPO
HORRORIZADO
[Blanco]
Figura 1:
Miedo.
Figura 2:
Horror.
Figura 3: El
temor.
Figura 4:
Pasmo.
Figura 8: El
Femor.
Figura 5: La
huida.
Repugnante.
Angustia.
Figura
Pora
Figura 9: La repulsión. 
arqueado y descenso por las escaleras de forma antinatural, deformación total del rostro, cuello abultado.

Figura 12: Arrebato de la voz humana.

Figura 13: Poderes sobrenaturales.

Figura 14: El cuerpo se eleva sobre la cama.

Figura 15: Parásito creado genéticamente, parásito sanguinario.

Figura 16: Una mujer joven es portadora del parásito.

Figura 17: El parásito realiza violaciones corporales.

Figura 18: El parásito abandona los cuerpos de las víctimas por la boca.

Figura 19: Secreciones no humanas (ácido).

Figura 20: Criatura alienígena, caparazón de crustáceo y $\sin$ ojos.

Figura 22: Incubación huevecillos en los cuerpos humanos. de sangre humana.

Figura 12: Venganza.

Figura 13: Poder. sobre la naturaleza: Tiniebla /Niebla.

Figura 14: Posesión demoníaca.

Figura 15: Ruptura de todas las normas naturales y sociales.

Figura 16: Lo no humano.

Figura 17: Violentación de los cuerpos, se introduce por la vagina, invasión corporal del humano por un cuerpo no humano, la sexualidad aberrante.

Figura 18: Fuerza sobrehumana. 
La figurativización del cuerpo terrorífico reside en la ruptura de los confines de lo normalizado, por tanto, la figuratividad del cuerpo terrorífico está relacionado con: (a) lo anormal; (b) lo detestable; (c) la decadencia corporal; (d) la supuración y putrefacción goteante; (e) la decrepitud; (f) la no pertenecía a este mundo -natural vs. antinatural-; (g) lo carcomido; (h) lo chorreante, (i) el vómito cárnico; (j) lo no viviente-en-movimiento, entre otro elementos que se refieren en las sintaxis figurativas expuestas. A fin de cuentas, todas inciden en la construcción de un cuerpo horrífico.

La configuración del cuerpo horrendo se relaciona con aquello que hay que reprimir, pero también personifica lo no permisible ni aceptado socialmente. Quizá por eso las emociones que despierta el cine de horror son fascinantes porque fracturan los deseos y dejan en libertad a la imaginación. La fuente-cuerpo horrífico son los monstruos, las brujas, los fantasmas, los zombis, los demonios, los vampiros, los hombres lobo, los enfermos mentales, incluso, los androides, todos y cada uno de ellos son los causantes, en el blanco-cuerpo horrorizado, de la ansiedad, del miedo, de la neurosis, del terror, de la huida, entre muchas otras afectividades. Todo porque esos cuerpos horríficos son amenazantes, ya sea mediante el asesinato, las posesiones diabólicas, el vómito y las supuraciones. Ambos cuerpos, el terrorífico y el aterrorizado, se encuentran en atmósferas específicas tales como las pesadillas, los cementerios, las casas abandonadas, los bosques tenebrosos, los castillos en ruinas o los jardines decadentes. Sin olvidar los contrastes de luz-sombra y los tonos penumbrosos.

El cuerpo horripilante se describe en campos semióticos muy determinados, como la fealdad física extrema, las uñas largas, los dientes incisivos grades, los colores lívidos de la piel, como en el caso de los vampiros. No se puede soslayar que las mutaciones, las personas deformes, la bestialidad y lo sobrenatural, el ocultamiento y la destrucción violenta de ser humano son identificadas con el horror. Tradición de largo recorrido, desde el cine mudo de terror alemán con EI Gabinete del Doctor Caligari (1920), Nosferatu, el vampiro (1922) о El estudiante de Praga (1926), pasando por el cine de terror estadounidense con La legión de los hombres sin alma (1932), La mujer pantera (1942), La invasión de los ladrones de cuerpos (1956) o La mosca (1986), hasta llegar al terror moderno; al terror gótico italiano o el cine de terror oriental. Cada una de estas escuelas 
coinciden, mayor o menor grado, en exponer los confines de las normas del orden social y cómo estas, al ser fracturadas causan el temor, el sobresalto o la inquietud. Incluso, lo no monstruoso, en el cine hipermoderno, causa horror, como los cuerpos musculosos y narcisistas, pero caracterizados por la fealdad, lo siniestro y la monstruosidad moral, pero eso será otro tema de investigación para continuar con la configuración semiótica del cine de horror. Por lo pronto queda abierta la configuración del cuerpo horrorizado, incluso, la configuración del cuerpo de control, es decir, explicitación de los principios configurantes. Baste por el momento señalar que la Semiótica de cuarta generación ha proporcionado los dispositivos teóricos y metodológicos para describir los rasgos figurativos del cuerpo terrorífico en el cine de horror

\section{Referencias:}

Benveniste, Émile (2004). Problemas de lingüística general, tomo 2. Tr. Juan Almela. México: Siglo XXI.

Benveniste, Émile (2007). Problemas de lingüística general, tomo 1. Tr. Juan Almela. México: Siglo XXI.

Coppola, Francis Ford (1992) Drácula. [Película, 128 min.]. Estados Unidos: Columbia Pictures.

Corbin, Alain (2005). Historia del cuerpo: De la revolución francesa a la gran guerra. V.2, Taurus Ediciones: Madrid.

Courtés, Joseph (2007). Análisis semiótico del discurso. Del enunciado a la enunciación. Ver. española Enrique Ballón Aguirre. Madrid: Gredos. (Biblioteca Románica Hispánica).

Cronenberg, David (1986). La mosca. [Película, 96 min.]. Canadá, Reino Unido, Estados Unidos: Twentieth Century-Fox Productions

Cronenberg, David (1975). Vinieron de dentro... [Película, 87 min.]. Canadá: The Canadian Film Development Corporation.

Cuéllar Barao, Margarita (julio-diciembre, 2008). "La figura del monstruo en el cine de horror". En Revista CS, núm. 2. Cali, Colombia: Universidad ICESI. 227-246. Disponible en http://www.redalyc.org/pdf/4763/476348366007.pdf 
Descartes, René (1994). Discurso del método/ Tratado de las pasiones. Tr. Miguel Ángel Granda. Barcelona: RBA editores. (Historia de la literatura, 11).

Fontanille, Jacques (2001). Semiótica del discurso. Tr. Oscar Quezada Macchiavello. Perú: Universidad de Lima. (Colección Biblioteca Universidad de Lima).

Fontanille, Jacques (2008). Soma y sema. Figuras semióticas del cuerpo. Tr. Desiderio Blanco. Perú: Universidad de Lima. (Colección Biblioteca Universidad de Lima)

Friedkin, William (1975). El exorcista. Estados Unidos: Warner Sogefilms-Hoya Productions.

Galeen, Henrik (1926). El estudiante de Praga. [Película, 85 min.]. Alemania: Deutscche Bioscop $\mathrm{GmbH}$.

Gómez Alonso, Rafael (2001). Análisis de la imagen. Estética Audiovisual. Madrid: Ediciones Del Laberinto.

Greimas, Algirdas Julius y Courtés, Joseph (1982). Semiótica. Diccionario razonado de la teoría del lenguaje, tomo 1. Ver. española de Enrique Ballón Aguirre y Hermis Campodónico Carrión. Madrid: Gredos. (Biblioteca Románica Hispánica).

Greimas, Algirdas Julius. y Courtés, Joseph (2004). Semiótica. Diccionario razonado de la teoría del lenguaje, tomo 2. Ver. española de Enrique Ballón Aguirre y Hermis Campodónico Carrión. Madrid: Gredos. (Biblioteca Románica Hispánica).

Helperin, Victor (1932). La legión de los hombres sin alma. [Película, 67 min.]. Estados Unidos: Victor, Edward Halperin Productions.

Kubrick, Stanley (1980). El resplandor. [Película, 146 min.]. Reino Unido-Estados Unidos: Warner Bros. Pictures, Producers Circle, Peregrine, Hawk Films.

Marnau, Friedrich Wilhelm (1922). Nosferatu, el vampiro. [Película, 81 min.]. Alemania: Prana-Film. Myrick, Daniel y Sánchez, Eduardo (1999). El proyecto de la bruja de Blair. [Película, 86 min.]. Estados Unidos: Haxan Films.

Polanski, Roman (1968). La semilla del diablo. [Película, 136 min.]. Estados Unidos: William Castle Productions. 
Scott, Ridley (1979). Allien, el octavo pasajero. [Película, 117 min.]. Reino Unido-Estados Unidos: Twentieth Century-Fox Productions, Brandywine Productions.

Siegel, Don (1956). La invasión de los ladrones de cuerpos. [Película, 80 min.]. Estados Unidos: Allied Artits.

Tourneur, Jacques (1942). La mujer pantera. [Película, 73 min.]. Estados Unidos: RKO Radio Pictures. Wiene, Robery (1920). El Gabinete del Doctor Caligari. [Película, 63 min.]. Alemania: Decla Bioscop. 